\title{
Analysis changes of ecosystem pattern in Beijing Four Seasons Flower Valley
}

\author{
Xiaona Liu ${ }^{a}$, Hong Lib \\ Beijing Research \& Development Center for Grass and Environment, Beijing 100097, China \\ axnliu1986@163.com, blihsdf@sina.com
}

Keywords: Ecosystem pattern; Land use and land cover change; Beijing valley economy; Four Seasons Flower Valley (FSFV)

Abstract. Spatial-temporal changes of land use and landscape pattern dynamic of Four Seasons Flower Valley in Beijing mountainous area were analyzed from 2007 to 2013. The results showed that: Regional structure of ecosystems in FSFV was forest-farmland-grassland. Farmland was the dominant artificial type mainly located in the relative low altitude areas and along the major road, while orchard land was mainly surrounding farmland and construction land. During 2007-2013, all acreage of ecosystem types increased except forest and wetland. Farmland had the lowest increment of $14.85 \mathrm{hm} 2$ and was mainly converted into construction land, grassland and orchard land. Construction land had fastest annual growth rate of $2.37 \%$ followed orchard land of $1.93 \%$. Land use and land cover change was mainly occurred in cultivated land and shrubland which mostly were converted into orchard land and construction land. Ecological environment became slightly worse and landscape showed a trend of fragmentation interrupted by human activities. Adjustment of agricultural structure, land resources utilization, leisure tourism economy development and the building area occupation were the main driving forces.

\section{Introduction}

Ecological environment is the basis for human survival and economic and social sustainable development. Ecosystem pattern and its spatial changes reflect spatial distribution and structure characteristics of various ecosystem types. It is the vital factor for determining the overall situation and spatial differences of ecosystem services, and also the important reference for protection and utilization of ecosystem services in different regions [1]. Land use and land cover change is an important component and reason of global environmental change, and has the significant effects on regional climate, hydrology, biogeochemical cycles and biodiversity by changing the structure, spatial pattern and service function of ecosystem [2,3]. Mastering spatial-temporal changes of land use and land cover and ecosystem pattern and quality timely and dynamically has important scientific value and practical significance for regional ecological environment construction and ecological protection red line delineation, especially in the mountainous areas with the relative low level of socio-economic development $[4,5]$.

As ecological conservation area of the national capital, Beijing's mountainous area is the natural ecological barrier, water conservation region and bearing capacity of biodiversity. Restricted by tough geographical and natural conditions, it is also the region with economic underdevelopment. With the strength of human activities increasing, such as urbanization, industrialization and agricultural intensification, ecological environment and natural resources are faced with tremendous development pressure in those mountainous areas. The contradiction between socio-economic development and ecological environment protection becomes relative prominent and acute nowadays. Ecological economization and economic ecologization is the hot issue currently [6]. With ecological protection as premise, aiming to drive local development, valley economy which was proposed officially in 2008 is industrial economic belt by unified development which takes natural valley of mountain as unit, and an important and effective way to break the bottleneck of the comprehensive arrangement and improvement rural and urban development in Beijing's mountainous areas [7]. Beijing has 179 valleys along with area more than $5 \mathrm{~km}^{2}$ covering total area of $10418 \mathrm{~km}^{2}$ with the percentage of $62 \%$ of 
Beijing City. According to the investigation of Beijing Municipal Commission of Rural Affairs, Yanqing District as the host site of 2022 the winter Olympics has 17 valleys with development potential [8]. With the development of the social economy in valleys, resources and environmental problems have become increasingly prominent. Ecological environment protection and ecological civilization construction becomes urgent and irreplaceable for regional sustainable development [4].

Four Seasons Flower Valley (FSFV), which is located in eastern mountainous region of Yanqing District, was listed as one of ten strategic growth pole construction of 'Demonstration Area of Green Beijing' in the 12th Five-Year Plan of Yanqing County. Meanwhile, it has also been listed as of seven key valleys in Beijing mountainous area in 2011. Valley economy in FSFV has obtained effective achievements, such as driving farmers' income, promoting leisure tourism, improving ecological environment, and becoming the sample of agriculture landscape in suburban areas of Beijing [9]. Based on high resolution remote sensing data of SPOT5 in 2007 and 2013, spatial-temporal changes of ecosystem pattern of FSFV were analyzed from land use and land cover change and landscape pattern perspectives. The purpose of this study was to provide a scientific basis for quantitative analysis of ecosystem pattern changes before and after valley economy announced towards ecological environment and reference for the coordination of economic and ecological benefits of sustainable development.

\section{Materials and methods}

\section{Study area}

Four Seasons Flower Valley (FSFV) is located in the eastern part of Yanqing District in Beijing mountainous areas, including Liubinpu Town (overall 16 villages), Sihai Town (overall 18 villages) and Zhenzhuquan Town (5 villages) from west to east (Fig.1). The complex topography with altitude ranging from $385 \mathrm{~m}$ to $1482 \mathrm{~m}$ formed the typical vertical climate change, which brings out the significant vertical distribution of plant communities with warm temperate deciduous broad-leaved forest dominating. This region has a temperate continental monsoon climate, with annual mean temperature $8{ }^{\circ} \mathrm{C}$ and annual average precipitation ranged from $550 \mathrm{~mm}$ to $700 \mathrm{~mm}$. The region cover $284.12 \mathrm{~km}^{2}$ accounting for $14.25 \%$ of the total area of Yanqing District $(2.73 \%$ of Beijing mountain areas) with ditch length of $47 \mathrm{~km}$ and a population of 16540 that has $45.88 \%$ of urbanization rate.

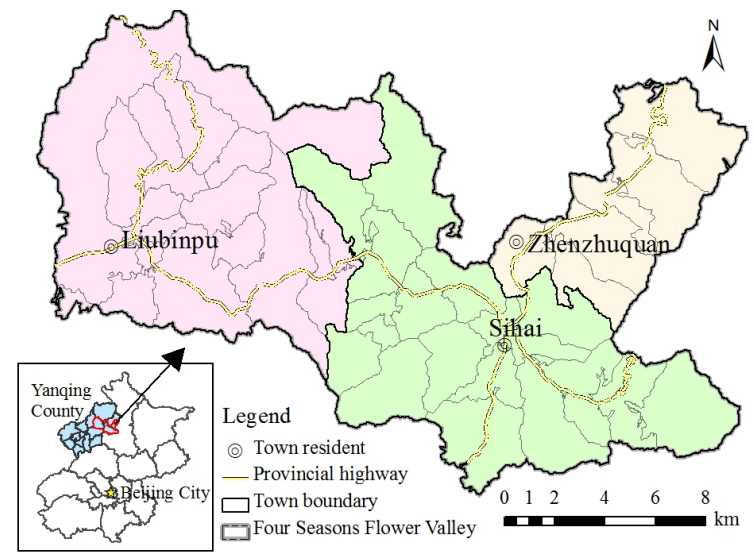

Fig. 1 The location of study area

\section{Ecosystem classification}

For the sake of comparing and analyzing the ecosystem pattern changes since valley economy promoting in 2008, land use and land cover classification maps were interpreted from SPOT5 in 2007 and 2013 adopting decision tree and visual interpretation method (Fig.2). Topographic maps with the scale of 1:10000 was used to geometric rectification remote sensing images. The system of land use and land cover has farmland, orchard land, woodland, shrubland, grassland, construction land, and wetland based on the ecosystem types and the characteristics of land resources and landscape changes according to the existing research results of Costanza et al. [10]. Ecosystem was divided into farmland, orchard, forest, grassland, construction, wetland types, whereby forest ecosystem including woodland 
and shrubland. The total classification accuracy of land use and land cover in 2007 and 2013 was more than $95 \%$ after verifying with the higher images from Google Earth images in the relevant years, which can meet the demand of spatial-temporal analysis and practical application (Fig.2).
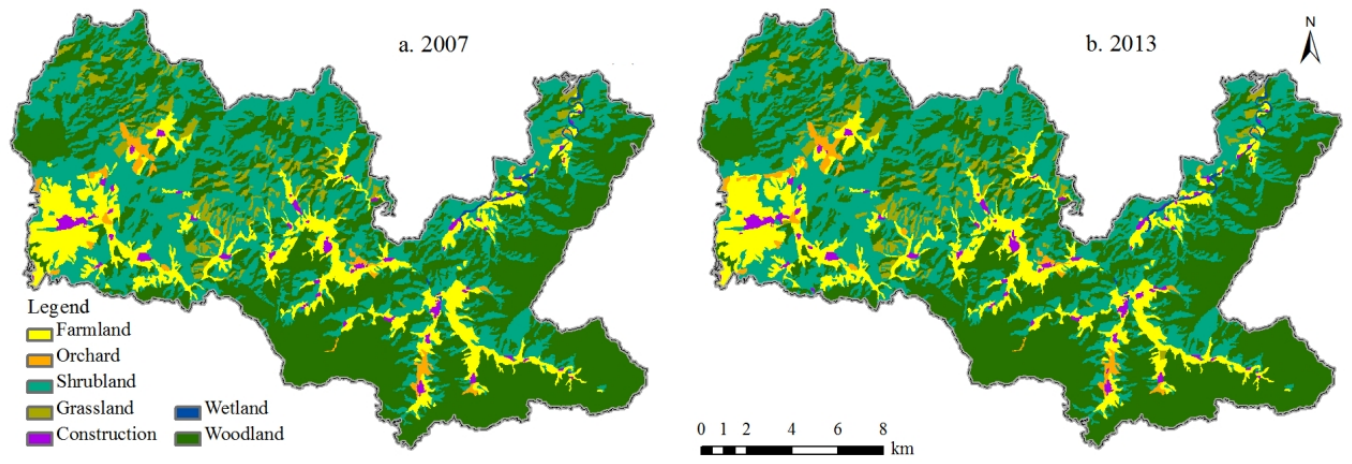

Fig.2 Classification maps of land use and land cover in FSFV from 2007 to 2013

\section{Methodology}

Ecosystem pattern change is composed of temporal change, spatial change and landscape change [11]. This study analyzed the quantitative and spatial changes of ecosystem pattern through adopting different indices and models using methods of overlay analysis towards GIS, statistical analysis and measurement analysis. Structural proportion, the single land use dynamic degree (K) degree [12] , matrix of transition probability, land cover change index (LCCI) [13], Edge Density, Contagion Index (CONTAG) and Shannon Diversity Index (SHDI) were used to reflect ecosystem pattern and landscape changes $[14,15]$. Ecosystem land cover change index (LCCI) reflects the overall trend in land cover types within a specific period. If it is positive, it means land cover type turn into better in study region. On the contrary, it means that the whole study area land cover type convert into worse $[14,16]$.

\section{Results and analyses}

\section{Spatial distribution and structural change of ecosystem types}

Based on the land use and land cover classification maps in 2007 and 2013, the quantitative characteristics of ecosystem types in FSFV were analyzed through the indices of acreage, structure, and the single land use dynamic degree of different types to grasp the general feature of the structural changes. FSFV located in the middle mountainous area of Yanqing District has obvious artificial ecosystem features. Regional structure of land use and land cover in study area was forest land-cultivated land-grassland, while woodland was the major land cover type with proportion beyond $44 \%$ (Table 1). Farmland ecosystem was the dominant artificial type with proportion more 12\% mainly located in the relative low altitude areas and along the road regions, while forest ecosystem was major natural type with proportion over $80 \%$. Orchard land was mainly occurred in the scope surrounding farmland and construction land. Between 2007 and 2013, forest land reduced by $0.42 \%$, while farmland, orchard land and construction land increased by $0.05 \%, 0.14 \%$ and $0.17 \%$, which indicated that the interruption by human activities on ecological environment became more frequent and remarkable since practicing valley economy mode in FSFV.

During year of 2007-2013, all ecosystem types increased except forest land and wetland (Table 1). To be specific, Farmland ecosystem had the lowest increment of $14.85 \mathrm{hm}^{2}$, with annual growth rate of $0.07 \%$. Area of orchard land was increased from $348.94 \mathrm{hm}^{2}$ to $389.35 \mathrm{hm}^{2}$, about increment of 40.41 $\mathrm{hm}^{2}$, along with structural proportion growing up $0.14 \%$ and dynamic degree of $1.93 \%$, which was the fastest growth type in FSFV behind construction land. Forest land area decreased from $23210.18 \mathrm{hm}^{2}$ to $23090.60 \mathrm{hm}^{2}$ with reduction of $119.88 \mathrm{hm}^{2}, 0.42 \%$ structural proportion and annual decreasing rate of $0.09 \%$, which was mainly resulted from shrubland reduction. Shrubland was the type with largest reduction of $122.22 \mathrm{hm}^{2}$ and annual decreasing rate of $0.19 \%$. Construction land was the type with largest increment of $0.17 \%$, and also the fastest growing type at the annual growth rate of $2.37 \%$. Wetland remained unchanged during those 8 years, has the acreage of $94.68 \mathrm{hm}^{2}$ accounting for $0.33 \%$ 
of the total area in FSFV. Structural changes and quantitative analysis of ecosystem types in FSFV showed that cultivated land, construction land and shrubland were influenced greatly by the adjustment of agricultural structure, land resources utilization, leisure tourism economy development and the building area occupation after promoting valley economy in 2008. Meanwhile, lots of ecological environment construction projects, such as Small Watershed Management, Conversion of Cropland into Forest Project have played a positive effect for grassland and woodland proportion increasing. However, LCCI value was $-0.12 \%$ between 2007 and 2013 which indicated that the ecological environment becoming slightly worse.

Table 1. Area change and dynamic degree of ecosystem types in FSFV

\begin{tabular}{ccccccc}
\hline \multirow{2}{*}{ Types } & \multicolumn{3}{c}{2007} & \multicolumn{2}{c}{2013} & \multicolumn{2}{c}{$2007-2013$} \\
\cline { 2 - 7 } & $\begin{array}{c}\text { Area } \\
{\left[\mathrm{hm}^{2}\right]}\end{array}$ & $\begin{array}{c}\text { Proportion } \\
{[\%]}\end{array}$ & $\begin{array}{c}\text { Area } \\
{\left[\mathrm{hm}^{2}\right]}\end{array}$ & $\begin{array}{c}\text { Proportion } \\
{[\%]}\end{array}$ & $\begin{array}{c}\text { Area } \\
{\left[\mathrm{hm}^{2}\right]}\end{array}$ & $\begin{array}{c}\text { Dynamic } \\
\text { degree [\%] }\end{array}$ \\
\hline Farmland & 3461.23 & 12.18 & 3476.08 & 12.23 & 14.85 & 0.07 \\
Orchard & 348.94 & 1.23 & 389.35 & 1.37 & 40.41 & 1.93 \\
Forest & 23210.48 & 81.69 & 23090.60 & 81.27 & -119.88 & -0.09 \\
Woodland & 12726.27 & 44.79 & 12728.61 & 44.80 & 2.34 & 0.00 \\
Shrubland & 10484.22 & 36.90 & 10361.99 & 36.47 & -122.22 & -0.19 \\
Grassland & 956.64 & 3.37 & 972.84 & 3.42 & 16.20 & 0.28 \\
Construction & 340.03 & 1.20 & 388.45 & 1.37 & 48.42 & 2.37 \\
Wetland & 94.68 & 0.33 & 94.68 & 0.33 & 0.00 & 0.00 \\
\hline
\end{tabular}

\section{Analysis of ecosystem types changes}

Ecosystems changes were not significant between 2007 and 2013 in FSFV. Land use and land cover change was mainly occurred in cultivated land and shrubland which mostly was converted into orchard land and construction land (Table 2). Farmland ecosystem transferred with largest transfer rate of $1.95 \%$, and mainly converted into construction land, grassland and orchard land with transfer proportion $1.16 \%$ (up to $59.49 \%$ of transfer region), $0.47 \%$ and $0.25 \%$. Newly-increased cultivated land was mainly explored from orchard land and shrubland which was close to roads and settlements easily for land development and utilization. Orchard land has $0.09 \%$ transfer rate occurring mainly into construction land and farmland, and mostly transformed from cultivated land and shrubland. Woodland didn't transfer during these 8 years, and mainly acquired from cultivated land because of the policy of Conversion of Cropland into Forest Project. Shrubland was converted 1.17\% into farmland, orchard land and construction land mostly, within the first two types accounting for $94.87 \%$ of overall transfer area. Grassland was similar with woodland in the conversion period. Construction land was mainly from farmland, garden plot and shrubland, among farmland was the main contribution with $83.08 \%$ source rate. The results of analysis of ecosystem types changes indicated that ecosystem type pattern was driving by agricultural structure adjustment and economic development obviously with the development of valley economy in FSFV resulted in significant transition between farmland and orchard land. Meanwhile, the development and utilization intensity of shrubland grew higher indicating influence of human activities on the ecological environment strengthening after implementing valley economy in FSFV.

Table 2. The transfer rate matrix of ecosystem types in FSFV from 2007 to 2013

\begin{tabular}{|c|c|c|c|c|c|c|c|}
\hline Types [\%] & $\begin{array}{c}\text { Farmlan } \\
\text { d }\end{array}$ & Orchard & Woodland & Shrubland & Grassland & Construction & Wetland \\
\hline Farmland & 98.05 & 0.25 & 0.07 & & 0.47 & 1.16 & \\
\hline Orchard & 0.21 & 99.10 & & & & 0.70 & \\
\hline Woodland & & & 100 & & & & \\
\hline Shrubland & 0.78 & 0.33 & & 98.83 & & 0.05 & \\
\hline Grassland & & & & & 100 & & \\
\hline Construction & & & & & & 100 & \\
\hline Wetland & & & & & & & 100 \\
\hline
\end{tabular}




\section{Analysis of landscape pattern of ecosystem types}

Number of Patch (NP), Edge Density (ED), Contagion Index (CONTAG) and Shannon Diversity Index (SHDI), which are reflecting landscape fragmentation and aggregation, were selected to analyze landscape changes of ecosystem types in FSFV (Table 3). The SHDI value was 0.6618 and 0.6776 in 2007 and 2013 respectively, which meant richer land use types and higher landscape fragmentation degree in FSFV since valley economy promotion. The physical meaning of NP and ED indices is the higher value, the higher fragmentation degree. Contagion Index (CONTAG) reflects the agglomeration degree or extend trend of different ecosystem types in landscape. Generally, high value of CONTAG indicates that ecosystem types hve formed a good connectivity; On the contrary, it indicates that the landscape shows fragmentation pattern. Construction land showed obvious fragmentation followed by farmland ecosystem, while forest and wetland ecosystem remained unchanged during those years, yet orchard land and grassland showed a trend of fragmentation.

Table 3. Landscape pattern indices in FSFV from 2007 to 2013

\begin{tabular}{ccccccc}
\hline Type & \multicolumn{2}{c}{$\mathrm{NP}$} & \multicolumn{2}{c}{ ED [m/hm $\left.{ }^{2}\right]$} & \multicolumn{2}{c}{ CONTAG [\%] } \\
\cline { 2 - 7 } & 2007 & 2013 & 2007 & 2013 & 2007 & 2013 \\
\hline Farmland & 73 & 78 & 16.55 & 16.85 & 75.00 & 73.99 \\
Orchard & 21 & 22 & 2.02 & 2.35 & 76.72 & 79.51 \\
Forest & 27 & 27 & 23.19 & 23.24 & 46.39 & 44.17 \\
Grassland & 107 & 109 & 7.83 & 7.93 & 72.41 & 72.60 \\
Construction & 55 & 65 & 2.56 & 2.99 & 73.37 & 71.72 \\
Wetland & 4 & 4 & 1.16 & 1.16 & 69.68 & 69.68 \\
\hline
\end{tabular}

\section{Conclusions}

Changes of land use and ecosystem pattern dynamic in Four Seasons Flower Valley (FSFV) were investigated and assessed by method of remote sensing and GIS integrated technology before (2007) and after (2013) the valley economy development mode promotion in 2008 by Beijing Municipal Commission of Rural Affairs. The results showed that:

(1) Regional structure of land use and land cover in FSFV was forest land-cultivated land-grassland. Farmland ecosystem was the dominant artificial type with proportion more $12 \%$ mainly located in the relative low altitude areas and along the road, while forest ecosystem was major natural type with proportion over $80 \%$. Orchard land was mainly occurred in the regions surrounding farmland and construction land.

(2) Between 2007 and 2013, all acreage of ecosystem types increased except forest and wetland. Farmland ecosystem had the lowest increment of $14.85 \mathrm{hm}^{2}$. Construction land was the type with largest increment of $0.17 \%$ and the fastest annual growth rate of $2.37 \%$ followed orchard land of $1.93 \%$. Shrubland was the type with largest reduction of $122.22 \mathrm{hm}^{2}$ and annual decreasing rate of $0.19 \%$. Ecosystem types changes were mainly occurred in farmland and shrubland which mostly were converted into orchard land and construction land. Landscape, as well as construction land, farmland and orchard land showed a trend of fragmentation. Those spatial and temporal changes of ecosystem types in FSFV indicated that the interruption by human activities on ecological environment became more frequent and remarkable since practicing valley economy mode in FSFV.

(3) Driving forces of ecosystem pattern changes were adjustment of agricultural structure, land resources utilization, leisure tourism economy development and the building area occupation. Although ecological environment in FSFV became slightly worse, but lots of ecological environment construction projects, such as Small Watershed Management, Conversion of Cropland into Forest Project have played positive effects already. 


\section{Acknowledgements}

This work was financially supported by the Project funded by China Postdoctoral Science Foundation and the Project funded by Beijing Postdoctoral Science Foundation, and Beijing Municipal Science \& Technology Plan Project (D131100000613002).

\section{References}

[1] R.J. Yang, B.J. Fu, G.H. Liu , et al.. Principles and methods of sustainable management of ecosystem. Chinese Journal of Ecology. 23(3): 103-108 (2004). (in Chinese)

[2] B.L Turner II. Socializing the pixel in LUCC. LUCC Newsletter. (1): 10-11 (1997).

[3] B.J Fu, S. Wang, C.H Su, et al.. Linking ecosystem processes and ecosystem services. Current Opinion in Environmental Sustainability. 5(1): 4-10 (2013).

[4] B.J. Yang, J.X. Gao, and C.X. Zou. The strategic significance of drawing the ecological protection red line. China Development. 14(1): 1-4 (2014). (in Chinese)

[5] Y.X. Tian, X.N. Liu, H. Li, et al.. Rural development difference based on subjective and objective evaluation of life quality: A case of economically underdeveloped villages in Beijing mountainous area. Progress in Geography. 34(2): 185-196 (2015). (in Chinese)

[6] G.D. Xie and S.Y. Cao. Ecological economization and economic ecologization in succession progress of development. Resources Science. 32(4): 782-789 (2010). (in Chinese)

[7] Y.F. Zhang, D.M.Jia, J. Tan J, et al.. The spatial structure of valley economy development in the mountainous areas of Beijing. Acta Geographical Sinica. 64(10): 1231-1242 (2009). (in Chinese)

[8] J.H. Chen, H. Li, and L.D. Zhou. Gully economy development's exploration and practice in Beijing mountain area. Ecological Economy. (1): 57-62 (2010). (in Chinese)

[9] J.H. Chen, Z.J. Yi, and J. Cao. Studies on construction mode of valley area economic in Beijing based on typical investigation. Journal of Agricultural Science and Technology. 14(6): 12-18 (2012). (in Chinese)

[10] R. Costanza, R. d'Arge, R. de Groot, et al.. The value of the world's ecosystem services and natural capital. Nature. 387(6630): 253-260 (1997).

[11] H.Y. Zhu, S.J. He, and M. Zhang. GIS spatial analysis and its application in the research of land use change. Progress in Geography. 20(2): 104-110 (2001). (in Chinese)

[12] X.L. Wang and Y.H. Bao. Study on the methods of land use dynamic change research. Progress in Geography. 18(1): 81-87 (1999). (in Chinese)

[13] Z.R. Yang, C. F. Wu, Y. Liu, et al.. Research on response of ecosystem to changes in land use in rapid urbanization areas - a case study of Zhejiang Province. Journal of Zhejiang University (Agric. \& Life Sci.). (3): 341-346 (2008). (in Chinese)

[14] W. Deng, H. Liu, X.Z. Yuan, et al.. Spatial-temporal changes of ecosystem pattern in the Three Gorges Reservoir water conservation area. Resoures and Environment in the Yangtze Basin. 24(4): 661-668 (2015). (in Chinese)

[15] X.Z. Li, R.C. Bu, Y. Chang, et al.. The response of landscape metrics against pattern scenarios. Acta Ecological Sinica. 24(1): 123-134 (2004). (in Chinese)

[16] H.X. Huang, Y.P. Luo, F.R. Yin, et al.. Analysis on the driving forces of compositions and pattern changes of ecosystem in Human Province. Journal of Human Univeristy of Science \& Technology (Natural Science Edition). 30(2): 60-67 (2015). (in Chinese) 